\title{
FIVE YEARS LATER: WHY MORE GULF LAW SCHOOLS SHOULD ADD AN EXTERNSHIP PEDAGOGY
}

\section{BY MELISSA DEEHRING}

\section{Introduction: Qatar University College of Law Externship Program}

In 2011, Qatar University College of Law established the Externship Program [hereinafter, the Program], a new pedagogical course for the region designed to teach students real life lawyering skills and encourage their pursuit of legal careers while balancing Qatari history, identity, traditions, and customs. ${ }^{2}$ The course is unique in a variety of ways, including but not limited to the fact that it combines a traditional externship experience, typical in US law school curricula, with bi-weekly seminars regarding practical skills, legal ethics and career advice specifically tailored for a gender segregated undergraduate law program located in the Middle East. ${ }^{3}$

While the course initially encountered resistance, mainly from worried family members regarding their female loved ones' participation, the program has subsequently proven enormously successful in the Qatari community with a total of 390 students, almost 75 percent of

\footnotetext{
${ }^{1}$ All the contributions to this Insight are inspired by, and many of the individual authors supported by, Qatar National Research Fund's National Priorities Research Program Grant 6-459-5-050, the Rule of Law in Qatar and the Arab Gulf Project. We acknowledge the invaluable assistance of Noha Aboueldahab, Sarah KofkeEgger, Susan Newton, Gwenn Okruhlik, Lubna Sharab, Sylvain Taouti and RA's at Qatar University and the University of Massachusetts-Amherst.

${ }^{2}$ See Deehring M. The push for practical legal skills education in Qatar: Results from an externship program, International Review of Law 2016:10 http://dx.doi.org/10.5339/irl.2016.10. pp1-17, 2.

${ }^{3}$ See Id.
} 
them female, participating in the program and competing for externship experiences with almost 100 different employers. $^{4}$

\section{Results Achieved}

The Program has hosted students since spring semester 2012, during which time it has seen unprecedented growth. ${ }^{5}$ From a small program that initially hosted 12 students competing for 18 jobs with 15 different employers during a semester, merely nine semesters later, the program hosted 94 students who competed for 142 jobs with 62 different employers during one semester (683\% increase in students per semester, 689 percent increase in jobs per semester, and 313 percent increase in participating employers per semester). ${ }^{6}$

A significant contribution of the Program has been the amount of data it has collected for use by the College and University concerning student and employer participation. ${ }^{7}$ As for employers, during all nine semesters, total participation by lawyers working in-house for companies has been about 34 percent, participation by lawyers working for various governmental ministries and entities (including Public Prosecution) has been about 25 percent, participation by local Qatari law firms has been about 19 percent and participation by international law firms has been around 17 percent. ${ }^{8}$ Yet interestingly, the number of students trained by category of employer does not directly correspond to that category of employer's rate of participation. For example, the Program has seen a significant amount of students choose to

\footnotetext{
${ }^{4}$ See Id.; see also Melissa Deehring, Paper Presentation, Encouraging Diversity in the Middle East; How an Externship Program is Changing the Face of the Qatari Legal Profession, International Legal Ethics Conference VII, Fordham Law School, New York City (July 14, 2016).

${ }^{5}$ Deehring M. The push for practical legal skills education in Qatar: Results from an externship program, International Review of Law 2016:10 http://dx.doi.org/10.5339/irl.2016.10. pp1-17,14.

${ }^{6}$ Deehring M. The push for practical legal skills education in Qatar: Results from an externship program, International Review of Law 2016:10 http://dx.doi.org/10.5339/irl.2016.10. pp1-17, 14.; see also Melissa Deehring, Paper Presentation, Encouraging Diversity in the Middle East; How an Externship Program is Changing the Face of the Qatari Legal Profession, International Legal Ethics Conference VII, Fordham Law School, New York City (July 14, 2016).

${ }^{7}$ Deehring M. The push for practical legal skills education in Qatar: Results from an externship program, International Review of Law 2016:10 http://dx.doi.org/10.5339/irl.2016.10. pp1-17, 14.

${ }^{8}$ Deehring M. The push for practical legal skills education in Qatar: Results from an externship program, International Review of Law 2016:10 http://dx.doi.org/10.5339/irl.2016.10. pp1-17, 14.; see also Melissa Deehring, Paper Presentation, Encouraging Diversity in the Middle East; How an Externship Program is Changing the Face of the Qatari Legal Profession, International Legal Ethics Conference VII, Fordham Law School, New York City (July 14, 2016).
} 
train in social welfare organizations despite social welfare organizations only comprising about 4 percent of the total participating employers. $^{9}$

\section{Employer Participation during Nine Semesters}

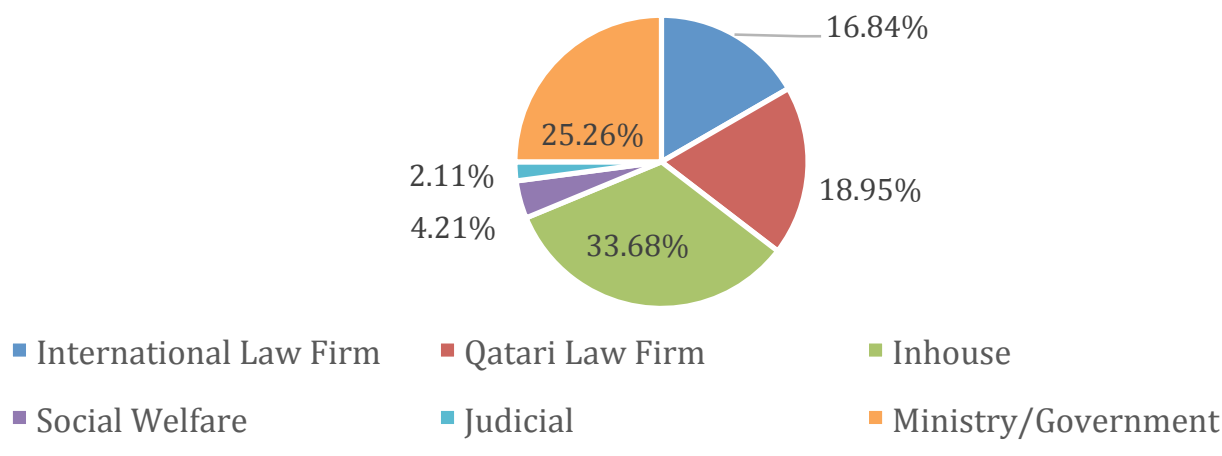

Fig. 1. Breakdown of Total Employer Participation in the Program by Category of Employer

Students' Participation during Nine Semesters

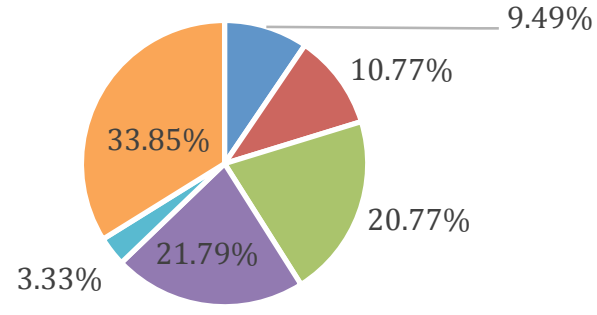
- International Law Firm " Qatari Law Firm
Inhouse
- Social Welfare
- Judicial
- Ministry/Government

Fig. 2. Comparison of Employer Participation and Students Trained by Category of Employer

When the Program has broken the data down further, we have been able to see that male and female choices for workplace trainings have varied significantly. ${ }^{10}$ The data shows male students have overwhelmingly favored Ministry or governmental trainings over private trainings, while

\footnotetext{
${ }^{9}$ Deehring M. The push for practical legal skills education in Qatar: Results from an externship program, International Review of Law 2016:10 http://dx.doi.org/10.5339/irl.2016.10. pp1-17, 14.

${ }^{10}$ Deehring M. The push for practical legal skills education in Qatar: Results from an externship program, International Review of Law 2016:10 http://dx.doi.org/10.5339/irl.2016.10. pp1-17, 15.
} 
the female students have favored social welfare trainings more than their male counterparts. ${ }^{11}$ As an example, for every semester that a social welfare organization has participated, on average 28 percent of the total students in the female class have decided to train with them while only an average of 4 percent of the total students in the male classes have done the same. Similarly, on average while a typical female class sees no more than one category of employer receiving more than 33 percent of the female students, the male classes regularly see less diversity in employment choices.

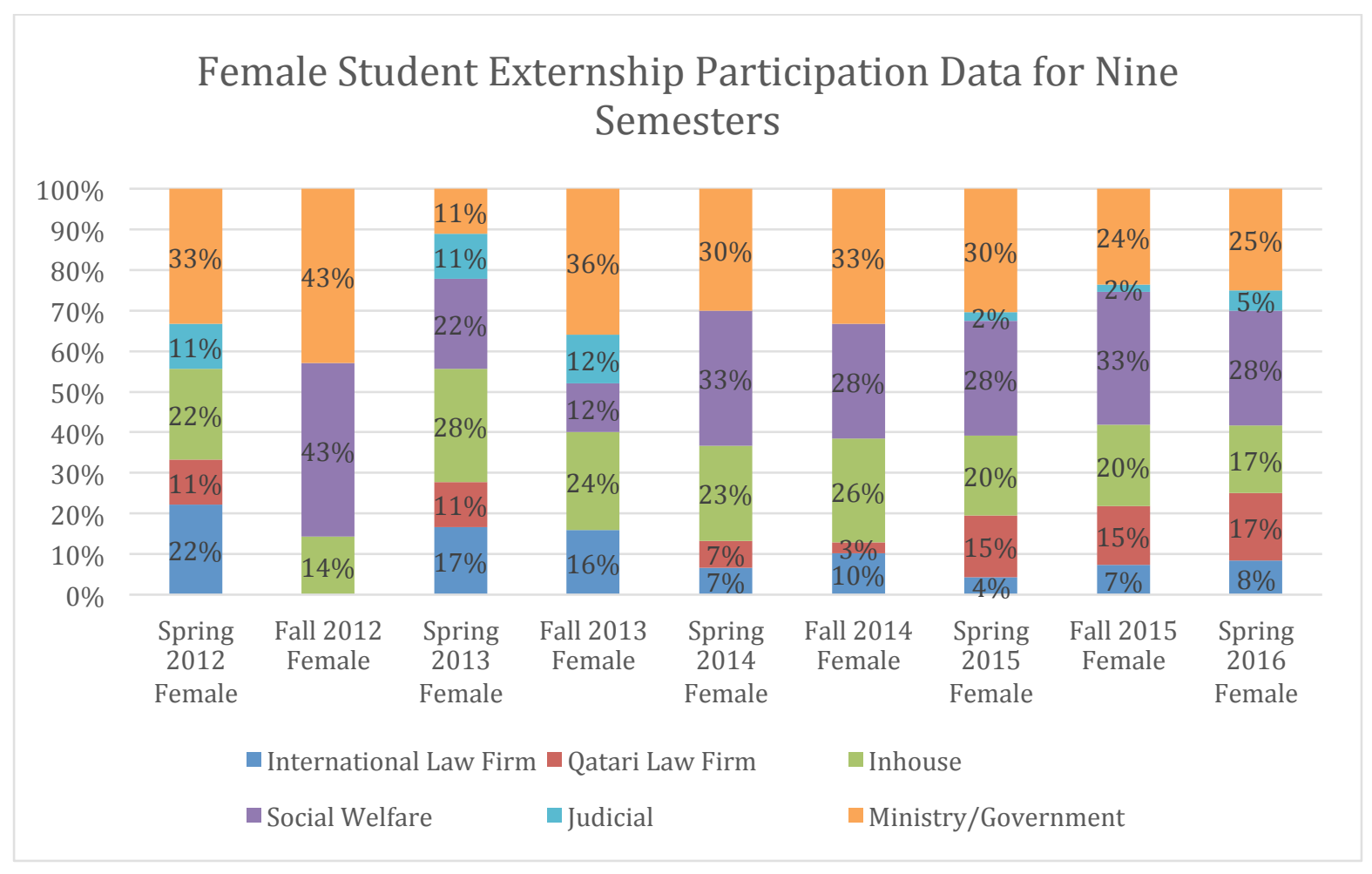

Fig. 3. Female students participation organized by category and semester during nine semesters

\footnotetext{
${ }^{11}$ See Id.
} 


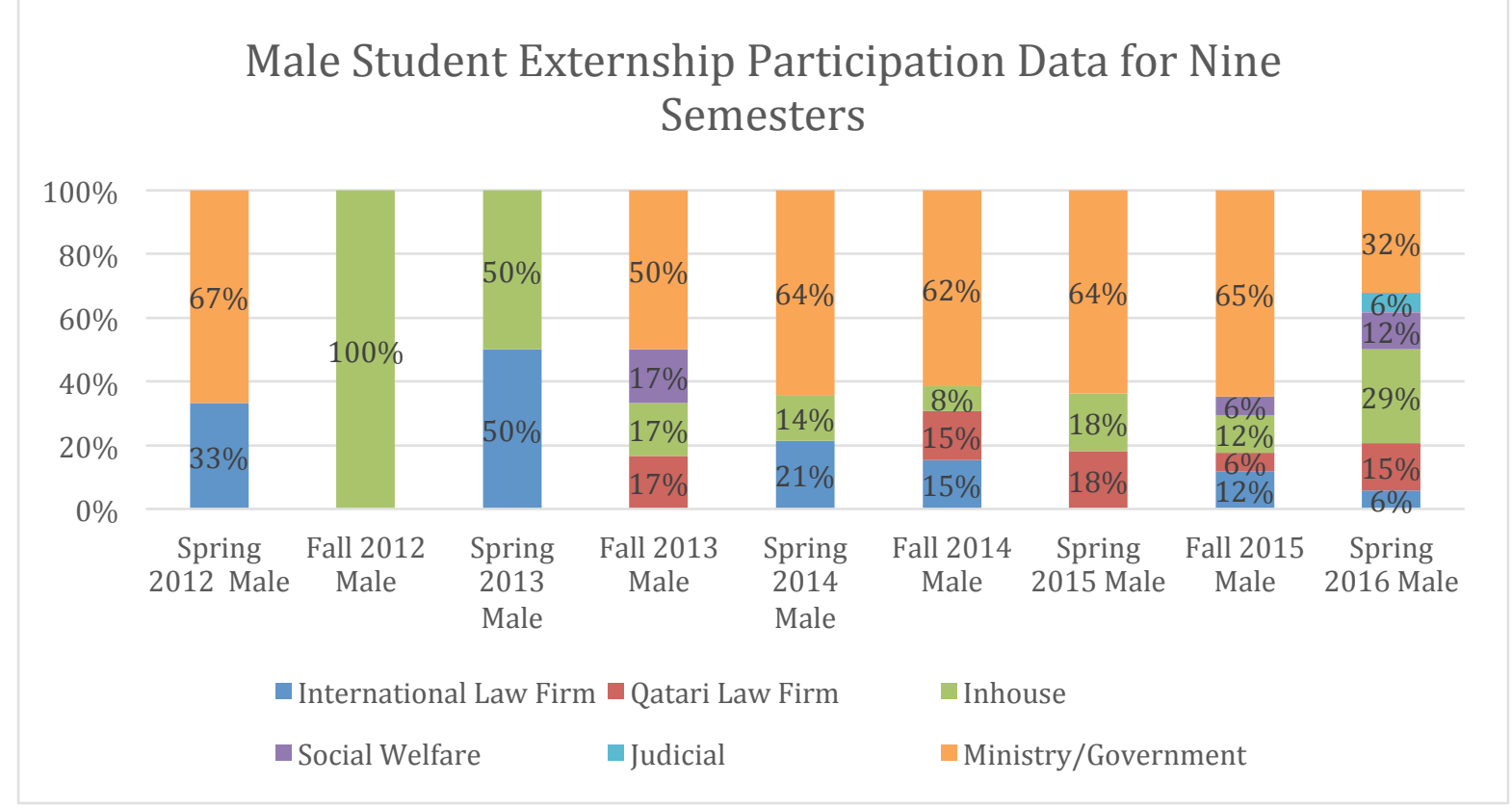

Fig. 4. Male students participation organized by category and semester during nine semesters As for job offers, since fall semester 2014 the Program has asked all employers whether they would hire their student externs after completion of the externship. ${ }^{12}$ While no follow-up data exists to see if the employers have actually followed up on their preferences, a majority of employers for all four semesters have indicated that they would hire their students. ${ }^{13}$ Interestingly, when data is broken down between sexes, female classes have slightly higher results than the male classes and certain categories of employers have indicated hiring preferences by gender (Fig 6). ${ }^{14}$ As an example, when polled at the end of the semester, the Ministry or governmental trainings have expressed a significantly higher interest in hiring their female students than their male students (Fig 7). ${ }^{15}$ What makes this noteworthy is that during all nine semesters more than 50 percent of the male students have decided to train with a Ministry or government entity, despite having what would be assumed lower chances of securing a position, while only 28 percent of female students have done the same. ${ }^{16}$ Additional research will help explain whether these preferences can be attributed to the male students' lack of knowledge

\footnotetext{
${ }^{12}$ Deehring M. The push for practical legal skills education in Qatar: Results from an externship program, International Review of Law 2016:10 http://dx.doi.org/10.5339/irl.2016.10. pp1-17, 15.

${ }^{13} \mathrm{Id}$.

${ }^{14}$ Melissa Deehring, Paper Presentation, Encouraging Diversity in the Middle East; How an Externship Program is Changing the Face of the Qatari Legal Profession, International Legal Ethics Conference VII, Fordham Law School, New York City (July 14, 2016).

${ }^{15} \mathrm{Id}$.

${ }^{16} \mathrm{Id}$.
} 
regarding these statistics, socially engrained feelings regarding government employment, and/or whether government employer responses on our evaluations accurately reflect actual hiring rates. $^{17}$

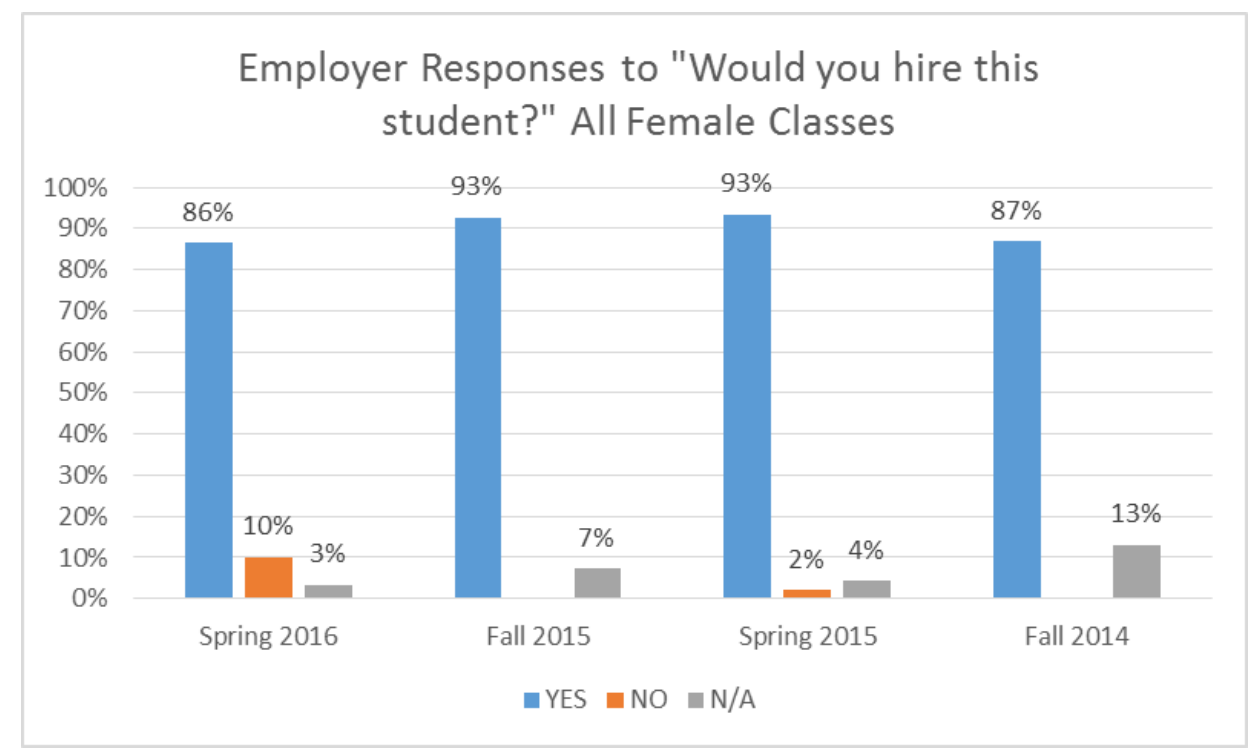

Fig. 5. Employer Responses to the question "Would you hire this student?" on female final evaluations

\footnotetext{
17 In fact, the author has used this and other information from Qatar's Externship Program to develop NPRP Proposal No.: NPRP9-341-5-047, which was recently awarded a two-year grant by the National Priorities Research Fund to: 1) outline the legal industry in Qatar and reported skills gaps for law grads; 2) study the career expectations of law students and provide an assessment of whether realistic or not; and 3) study the legal job market for entry level lawyers (with an emphasis on young female lawyers) and compare to number of law students in Qatar. For more information about this project, now sponsored by the Qatar National Research Fund, see http://www.qnrf.org/en-us/.
} 


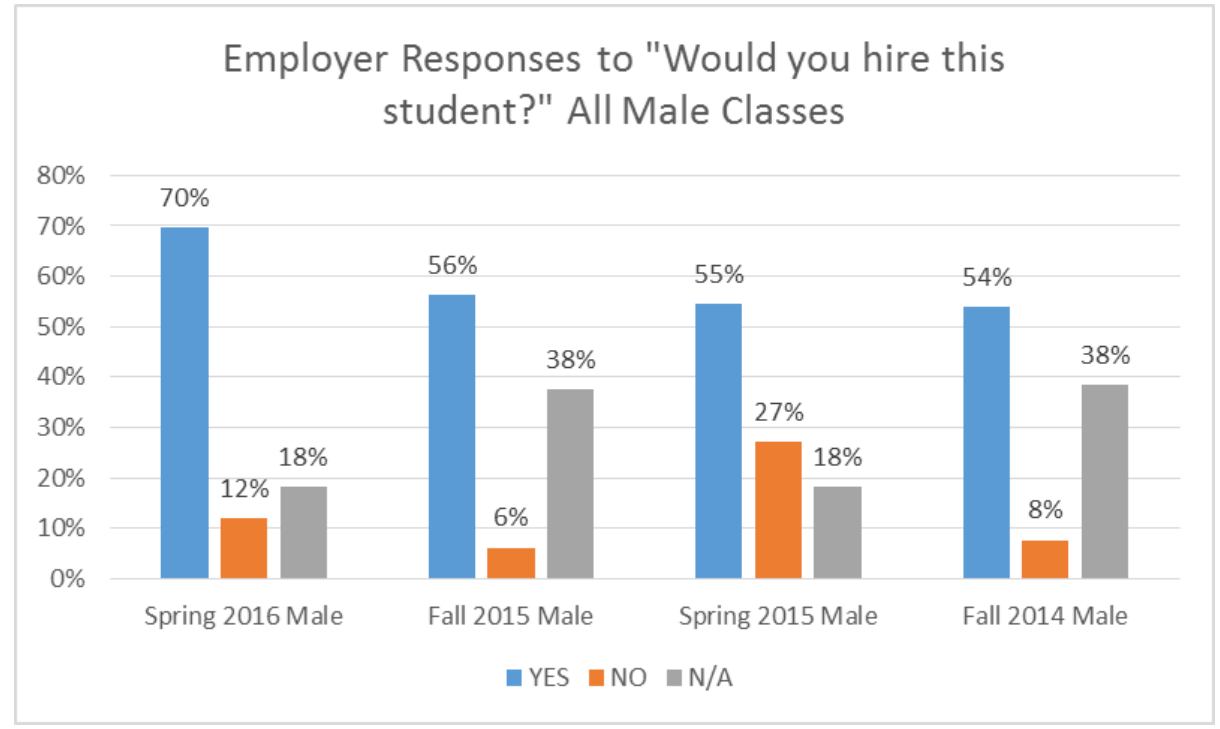

Fig. 6. Employer Responses to the question "Would you hire this student?" on male final evaluations

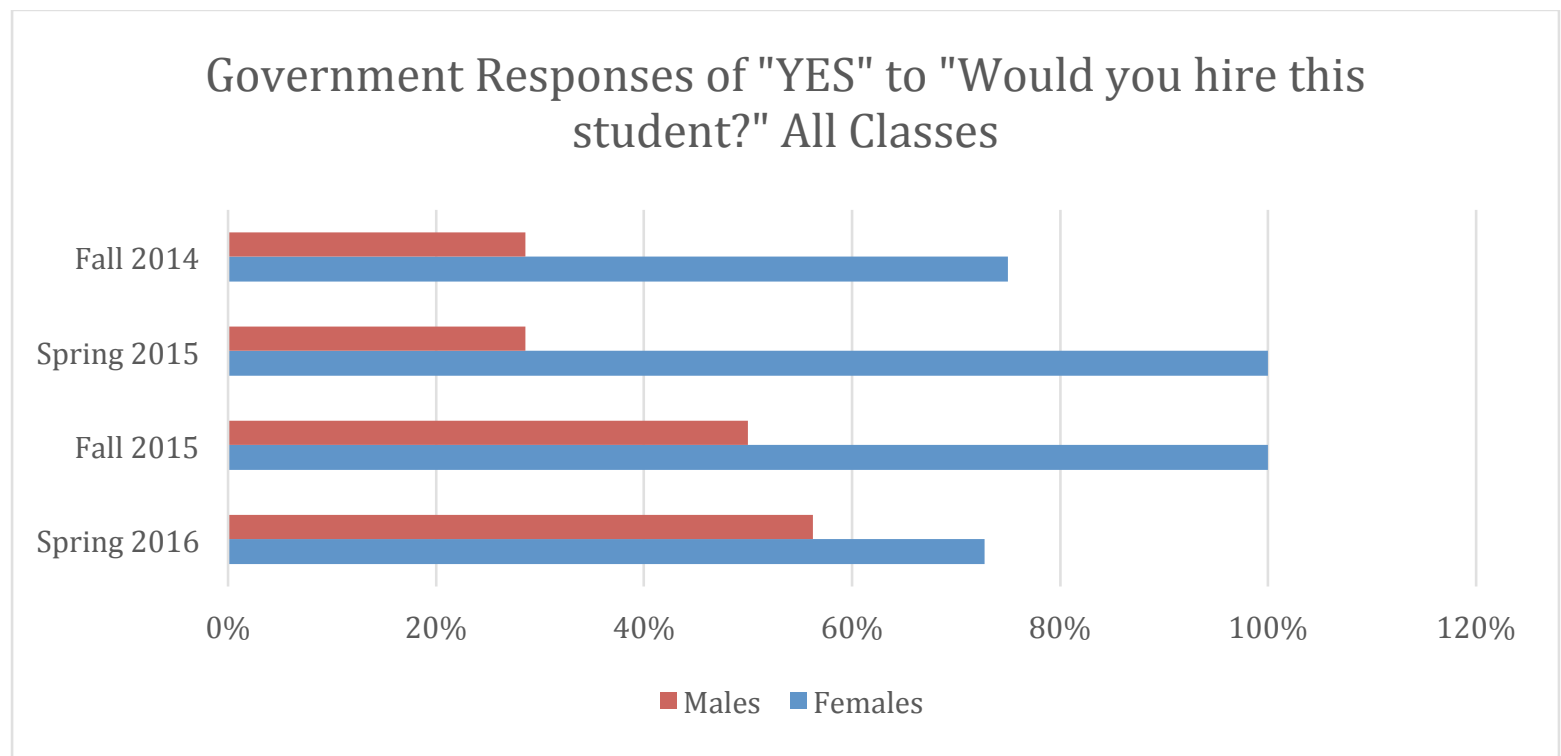

Fig. 7 Positive Ministry/Government Employer Responses to the question "Would you hire this student?" 
Another result of the Program has been a significant increase in self-reported post-graduation employment by law graduates. ${ }^{18}$ The increase in reported post-graduation employment can be directly seen through results reported by the Undergraduate Alumni Survey Report for December $2013 .{ }^{19}$ Figure 27 of the report shows that for the previous Alumni Survey finished in 2009-2010 the Employment Rate within One Year of Graduation for the LAWC was 49 percent. ${ }^{20}$ Three years later, after the Externship Program began operations, the Employment Rate within One Year of Graduation for law students was 91 percent, $^{21}$ an increase unseen by any of the other six Colleges at Qatar University. ${ }^{22}$

\section{- Employment Rate within One Year by Cycle and College}

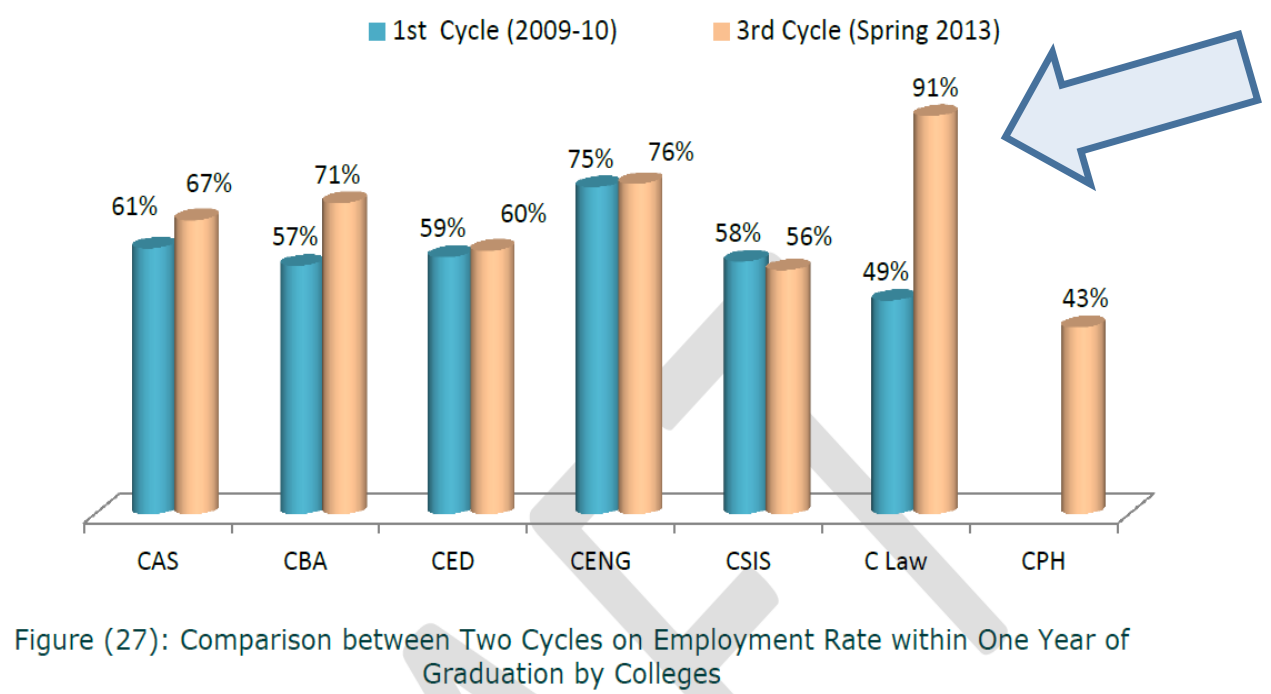

Fig. 8. Screenshot of Figure 27 from the 2013 Undergraduate Alumni Survey Report Draft with arrow added

\footnotetext{
${ }^{18}$ Deehring M. The push for practical legal skills education in Qatar: Results from an externship program, International Review of Law 2016:10 http://dx.doi.org/10.5339/irl.2016.10. pp1-17, 15.

$19 \mathrm{Id}$.

${ }^{20}$ Id., see also Survey Section Team, Institutional Research Department, Office of Institutional Planning \& Development at Qatar University, 2013 Undergraduate Alumni Survey Report, 28 (December 2013) (draft version on file with author). See also pages 62-64 of the Report for additional College of Law information, including the response rate of survey respondents.

${ }^{21}$ Id.

${ }^{22}$ See Survey Section Team, Institutional Research Department, Office of Institutional Planning \& Development at Qatar University, 2013 Undergraduate Alumni Survey Report, 28 (December 2013) (draft version on file with author).
} 
Finally, while employer participation, program growth, and post-graduation employment are important institutional achievements, the students themselves have directly reported arguably the most important results. ${ }^{23}$ When more than 90 students who participated in the Program during AY 2015-2016 were asked to evaluate themselves, a significant majority reported boosts in selfconfidence and strong feelings about how much of their self-growth could be attributed to the Program. $^{24}$

Specifically, more than 96 percent of male and female students reported that the Program directly helped them improve by being better prepared when arriving at work or beginning a project "quite a bit" or "a lot." 25 Additionally, almost 93 percent of students reported that the Program directly helped them improve and demonstrate a more mature and professional attitude "quite a bit" or "a lot" and more than 92 percent reported the Program directly helped them improve and develop better professional relationships to the same extent. ${ }^{26}$

Given the context and the initial struggles to establish the Program, the students' selfreported results become even more meaningful when analyzing the data provided by the more than 75 female students. These responses indicate that more than 90 percent of the female students believed the Program directly helped them improve in seven of the eight categories "quite a bit" or "a lot". 27

\footnotetext{
${ }^{23}$ Deehring M. The push for practical legal skills education in Qatar: Results from an externship program, International Review of Law 2016:10 http://dx.doi.org/10.5339/irl.2016.10. pp1-17, 16.

${ }^{24}$ See Id., see also Melissa Deehring, Paper Presentation, Encouraging Diversity in the Middle East; How an Externship Program is Changing the Face of the Qatari Legal Profession, International Legal Ethics Conference VII, Fordham Law School, New York City (July 14, 2016).

${ }^{25}$ Id.

${ }^{26} \mathrm{Id}$.

${ }^{27}$ The feedback from 76 female students who completely filled out their self-evaluation forms in Arabic or English report the following results: 91.75 percent for improving and demonstrating a more mature and professional attitude; 96.30 percent for improving and developing better professional relationships; 95.37 percent for improving and developing better time management skills; 88.64 percent for improving and developing better creative problem solving skills; 99.07 percent for being better prepared when arriving at work or beginning a project; 91.25 percent for paying more attention to detail and developing better proofreading skills; 95.88 percent for learning how to better communicate; and 94.44 percent for learning how to better focus and complete tasks.
} 

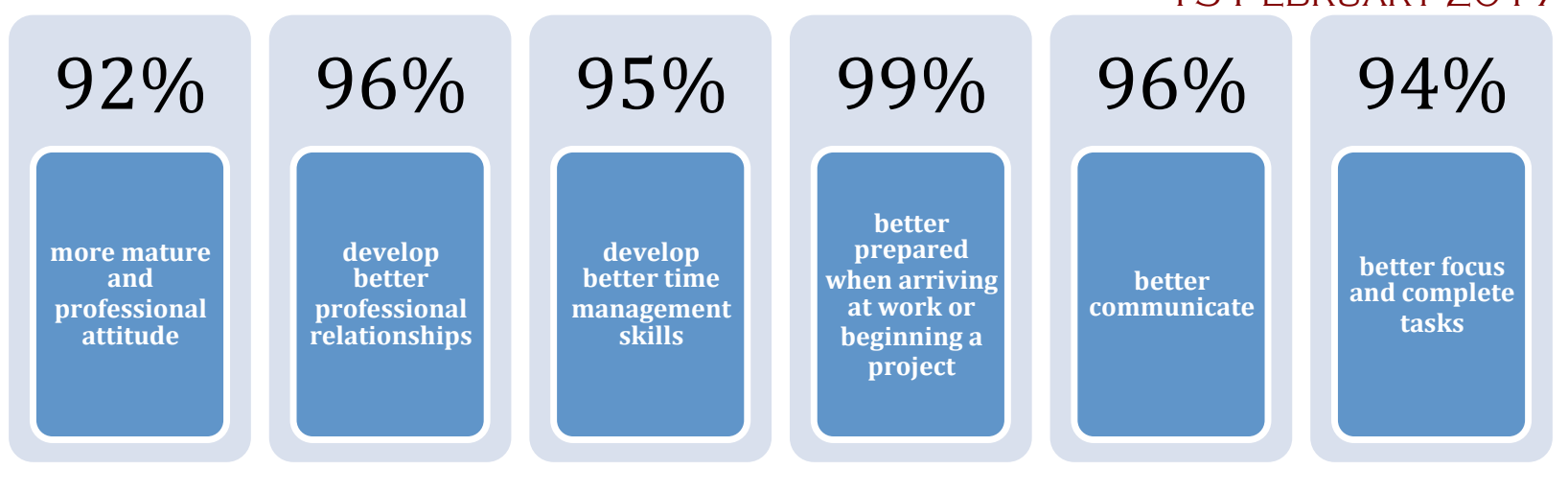

Fig. 9. Female Students' Self-Reported Growth of "A lot" or "Quite a Bit" Directly Due to the Program; Feedback from 76 Female Students During Academic Year 2015-2016

\section{Argument}

The wealth of data, information, relationships, partnerships, experiences, and opportunities the Externship Program has created in Qatar during its brief existence stands to show that the pedagogy in the Middle East and similar regions is more than possible and positive results are achievable so long as sufficient tailoring efforts are made to address cultural and sociological barriers. $^{28}$

Educators seeking to establish similar programs in the Gulf Cooperation Council region should expect to initially encounter resistance from students, families, local legal communities, and possibly even colleagues or university management. ${ }^{29}$ Expect to field phone calls from concerned parents; to have employers, sometimes even whole categories of employers, choose not to participate due to the nature of the program; to have students absolutely refuse to work in a mixed-gender office or with a certain category of employer due to personal or family reasons; to have issues relating to chaperones accompanying female students to interviews and the first few weeks of work; to have issues related to transportation of students, most likely female students who may be unable to drive to work and may not have a family driver available; to have some employers openly reject or refuse to interview students based on citizenship or tribe as this is not an unlawful practice in the Gulf; and to have many meetings pitching and cheerleading the concept in the community while explaining the differences between a supervised academic

\footnotetext{
${ }^{28}$ See Deehring M. The push for practical legal skills education in Qatar: Results from an externship program, International Review of Law 2016:10 http://dx.doi.org/10.5339/irl.2016.10. pp1-17.

${ }^{29}$ See Deehring M. The push for practical legal skills education in Qatar: Results from an externship program, International Review of Law 2016:10 http://dx.doi.org/10.5339/irl.2016.10. pp1-17.
} 
externship course and an after-school or summer internship with some organizations and administrators choosing ultimately not to officially recognize the differences and/or support the program. To combat this resistance, it is critical for the educator to immediately implement certain standards, safeguards, contracts, and waivers, and to set realistic short and long-term goals for data collection and/or program achievements that will serve to legitimize and highlight the educational value of the program. ${ }^{30}$

Once established, externship classes create solid relationships between academics, industry stakeholders and alumni that, when fostered, may serve as the basis for more scholarship, increased involvement by alumni, local practitioners, and local public servants, as well as the possible creation of more clinical and practical skills programs designed to address local access to justice and skills gap issues. ${ }^{31}$ Students in Qatar have responded favorably to this type of pedagogy, with many of them already requesting more clinical classes and reporting significant boosts in self-confidence and better professional attitudes as a result. ${ }^{32}$ There are 40 bachelor law programs in Kuwait, Saudi Arabia, Oman, the UAE, Bahrain, and Qatar as well as 49 programs offering Masters or Doctoral level legal studies. ${ }^{33}$ Our law students in the G.C.C. are ready; it is now time for us legal educators to create more experiential learning opportunities and help them thrive.

Melissa Deehring is the founder and Director of the Externship Program and Clinical Assistant Professor of Law with Qatar University (QU) College of Law in Doha. She Deehring received her BA and BSJ from Ohio University and her JD from Golden Gate University School of Law. Professor Deehring has negotiated agreements with more than 80 legal employers in Doha, developed clinical curricula, taught practical skills lectures, restructured the course as the "Capstone" graduation requirement for the College, established an annual law-specific career fair, and worked on a wide variety of academic committees. Prior to her international work, Melissa was a courtappointed defense counsel on juvenile dependency cases assigned by the San Francisco Superior Court.

\footnotetext{
${ }^{30}$ Id. at 17.

${ }^{31} \mathrm{Id}$.

${ }^{32} \mathrm{Id}$.

${ }^{33}$ Many thanks to Ms. Fatema M. Al-Mesleh, my teaching assistant and research assistant, for compiling this information. See: Kuwait: http://kilaw.edu.kw/, see also http://law.kuniv.edu.kw/; Saudi Arabia: http://forum.kau.edu.sa/vb/ssaie-caauaca-enceu-70/ssa-aciioo-cathcaeaeae-ecaaaasse-caaicaca-112476/; Oman: http://www.squ.edu.om/law, see also http://www.soharuni.edu.om/default/index.php/ar/study-ar/undergraduateprograms-ar/law-ar; UAE: https://www.caa.ae/caa/DesktopModules/InstPrograms.aspx; Bahrain: http://moedu.gov.bh/hec/UploadFiles/Progs-23-3-2016-En.pdf; Qatar: http://www.qu.edu.qa/law/, see also http://www.hbku.edu.qa/JurisDoctor.
} 